\title{
Philosophical Foundations of Ecological Ethics
}

\author{
Hryhorii Vasianovych ${ }^{1}$, Olena Budnyk*2, Hasrat Arjjumend ${ }^{3,4}$ \\ ${ }^{1}$ Federal Lviv State University of Life Safety, Ukraine \\ ${ }^{2}$ Vasyl Stefanyk Precarpathian National University, Ivano-Frankivsk, Ukraine \\ ${ }^{3}$ Université de Montréal Faculté de Droit, Québec, Canada \\ ${ }^{4}$ Centre for International Sustainable Development Law, McGill University Faculty of Law, Canada \\ *Corresponding author (E-mail: olena.budnyk@pu.if.ua)
}

How to cite this paper: Vasianovych, H., Budnyk, O. and Arjjumend, H. (2018). Philosophical Foundations of Ecological Ethics. Grassroots Journal of Natural Resources, 1(2): 13-21. Doi: https://doi.org/10.33002/nr2581.6853.01022

Received: 19 October 2018

Reviewed: 18 November 2018

Provisionally Accepted: 20 November 2018

Revised: 11 December 2018

Finally Accepted: 15 December 2018

Published: 31 December 2018

Copyright $(2018$ by author(s) and

The Grassroots Institute.

This work is licensed under the Creative Commons Attribution International License (CC BY 4.0).

http://creativecommons.org/licenses/by/4.0/

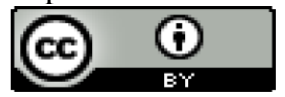

Open Access

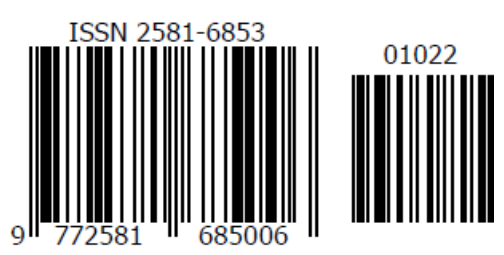

\begin{abstract}
This article substantiates the essence of ecological ethics in the context of modern scientific research. The emphasis lies on the need to develop a strategy and approach of human behavior amid the natural environment, rational nature management, protection and restoration of the surrounding world. The new methodological thinking is characterized by philosophical foundation of ecological ethics (ecological consciousness, ecological thinking, ecological values, ecological activity, etc.). The idea of development of environmental ethics based on principles of Christian and Philosophic noology is introduced. The world outlook is changing rapidly with its positive and negative aspects. It requires humanization of natural environment as well as a human being by forming ecological consciousness. There is a necessity of humanization of technosphere and abandoning technocratic thinking, which is anti-culture itself and, at times, it endangers human race on the Earth.
\end{abstract}

\section{Keywords}

Ecological Ethics; Noology; Knowledge of God; Knowledge of Nature; Knowledge of Human 


\section{Introduction}

The outlines of modern ecology are clearly defined in the literature. The ecology is believed to be a science about the environment, the peculiarities of interrelationships, and the interaction between the living and non-living components in a biophysical setting. Today, more than 100 different sub-disciplines of environmental research have emerged; and these can be organized in accordance of the principles of their branch affiliation, interconnectedness, mutual subordination, priority, theoretical and practical meaning. However, in this article, the concept of ecology as a science of survival can be proposed. It can be presented as a strategy for the conservation and development of life on the planet Earth. The ecological science, if analysed and synthesized appropriately, can model the development of ecological systems on the planet. It also helps adopt scientific, philosophical, ideological and ethical ways grounded in strategic plans for the development of the technosphere on Earth. In nutshell, this is the science that is dealing with today's real environmental problems such as pollution, waste, deforestation, climate change, drought and alike. These problems have arisen because of depletion of natural resources, unsustainable industrial practices, and decaying culture of nature protection. The people who are engaged in commerce are interested in business development only and disregard preservation of the natural environment.

To change human behavior towards natural environment and to ensure rational environmental management, environmental protection and ecosystems restoration, environmental research draws a scientific basis for workable strategy. It requires systematic organization of scientific efforts and implementation of ethical and ecological education across all people. However, the education does not correspond to the modern needs of human existence. Eventually, ecological ethics teaches about the need for radical change in consciousness of all people in a bid to reveal the essence and content of modern ecological morality, ecological conscience, and moral and spiritual relations between man and nature. Supporting the concept, Pope John Paul II underlines in "The Hundredth Year" that: "...besides the irrational destruction of the natural environment, it should be reminded of the more serious destruction of the human environment, which, however, do not pay due attention ... too little efforts are made to preserve the moral conditions of a true human ecology (John Paul II, 1993, p. 488). In fact, it turned out that the worst threats are not climate crisis and natural catastrophe, but an anthropological catastrophe which means the decay of humanity related qualities in a human being. Notably, questions surrounding the ecological and ethical role of human beings in protecting natural environment are rooted deep into philosophical, ideological and religious dimensions of the existence of humanity on the Earth.

Present article analyzes the philosophical principles of ecological ethics in contemporary contexts with the possibilities of humanization of the technosphere. It also explores the spiritual and moral influence on a human interacting and influencing ecosystem process of nature.

\section{The Essence of Environmental Ethics}

The scientists suggest the strategies for preserving the environment including soils (Amanuel, Yimer and Karltun, 2018), water resources (Danyliuk, 2018), national parks and forests (Arjjumend, Shibata and Fakana, 2018), plant ecology and mountain ecosystems (Körner, 2003), global climate change (Jeong et al., 2018). Arjjumend, Shibata and Fakana (2018) say, "human interference has been influencing conservation activities through accelerating the loss of habitat and biodiversity, which ultimately reduces the productivity of ecosystem services." They further 
highlight the threats to forest ecosystems from "illegal settlements, overgrazing, agricultural expansion, alien invasive species, bush encroachment, uncontrolled fire, overfishing, deforestation, degradation of wildlife habitats." On the other hand, Kostytskiy (2018) emphasizes that: "new role of the State in modern conditions is the ability of the State to respond to global challenges, using theoretical and legal science and law of sociology in the theological and sociological understanding of law". He further argues that "the post-industrial State, which still remains the mechanism of servicing the liberal values of society, must be replaced by an ecological state that can preserve democratic values" (Kostytskiy, 2018).

Following is the analysis of issues which is carried out along with certain identified issues as under:

a) the definition of the subject of ecological ethics - the essence of ethics lies in utilization of nature in one cultural tradition or another followed by the process of environmental education;

b) the principles and norms of Christian ethics;

c) systems of studying and managing the nature;

d) environmental ethics and human psychology;

e) ecological strategy of human survival; and

f) perspectives for the development of environmental ethics in view of a newly emerging reality.

Essentially, the reality of contemporary world has remarkably changed. We have to face new artificial reality created by humans such as the reality of cars, nuclear power stations, nuclear bombs, thermonuclear disasters and so on, and the reality of nature is reduced by the human himself. In such paradoxical situations, importance and role of the environmental ethics become more pertinent. The ecological ethics directs a person to attain realization of and connection with the nature through a spiritual principle. Giving value to the spiritual and moral aspects of nature and technology can overcome a person's attraction to the inanimate objects (Fromm, 1976; Schweitzer, 1992). As bioethics provides a critical intellectual input to the biomedical community, ecological ethics can help inform and improve ethical decision making in the field of ecology and conservation (Minteer and Collins, 2008). In this article, scope of environmental ethics confines to the spiritual and moral dimensions of human existence, which need to be considered imperative and transcendental.

\section{Christian and Philosophical Noology}

The term "noology" is derived from two Greek words: "noos" ("nous") and "logos". The word "logos" (meaning 'study') is widely used for a long time. Ukrainian philosophical dictionary characterizes the concept "nous" which "...plays an important role in Christian theology and anthropology (as the image of God in man)" (Shynkaruk,1986, p.453). Other authors define "nous" as a spirit that recognizes itself with a spiritual consciousness. Henceforth, noology is a Christian and philosophical doctrine of the spirit and spiritual essence of human being. It is the doctrine of a human as the image and likeliness of God, and of the trio interface of the body-soulspirit of a human. The image of God in human is the image of Absolute God Being. The spiritual basis of the personality is that everything in it is related and united within its noosphere through the sphere of God-like human spirit. Like other scientific disciplines, noology has its own attributes: the object and subject of research, the fundamental ideas and principles, the categorical apparatus, the theoretical and practical aspects of the research, the system and methods of 
research, etc. (Vasianovych and Onyshchenko, 2012, pp.3-4).

Christian and philosophical noology is based on the fundamental thought that God gave the Earth to mankind and a human must use the gifts of God wisely through his labour, spirituality and attitude. Noology demands that human's all activities should be creative, non-destructive, and constructive for both the nature as well as human. With the recognition of spirituality, it is time today to revise radically the idea of 'dominance over nature', which is dominant for centuries in western world. The consciousness uses to be sensitive to new ideas and new problems. Christian and philosophical noology states that any phenomenon that is not connected with the spiritual values, the values of goodness, beauty and truth falls out of the circle of culture and humanism. The progressive destruction of the environment is an unconditional manifestation of violations of ethical and environmental laws and norms, of the connection between natural and spiritual dimensions of a human existence, and of the fundamentals of meta-anthropological and noological principles. Today, the ideas are not only the actual anthropology, but also metaanthropology. The priest Dionysius Pavlo Lyakhovich notes, "In a meta-anthropology, which undergoes communication, self-transcendence and sacrifice, most important is how a person identifies the horizons to comprehend this discipline. A human is the being in whom all the worlds exist: the world of nature, the world of super-natural bodies, the world of consciousness and personality, and the world of self-transcendence, in which a human being is able to find the Absolute" (Lyakhovych, 1995, p. 82). It teaches us about nature knowledge and human knowledge.

Nature knowledge. From the point of view of Christian and Philosophical, noology is largely contrary to the present scientific knowledge of the world. When the scientific knowledge emphasizes mainly the worldview defined by the human mind, the noology concentrates on deep knowledge of the world of nature and outer space. Mystery of the world of visible and invisible requires the work of the whole human noosphere and the help of God. Within this circumference, we need to develop our understanding of the nature knowledge, and to develop the philosophy of ecology and environmental ethics, which are essentially linked to the prevailing scientific or natural dimensions of the world.

Today, in the philosophical works, the concept of "world" and "picture" change and acquire a new meaning. The "picture" in scientific representations often blurs. Well-known physicist Marc Planck (1958) wrote that the future picture of the world would be pale and cold compared to bright/colorful images of primitive world, nature and space. It is not accidental. The modern philosophers introduce the concept of "cold picture of the world" and "warm picture of the world." The cold picture of the world devoids ethical knowledge and ethical representation of the world in context of environmental ethics. It is created as an independent system of perception and understanding of the reality independent of the author. Additionally, Tsofnas (1995) notes in this context: "The cold picture of the world fulfilled its main function. It is possible to explain the world as an immanent system, as it does not need to realize its structure except for the predictable elements. This world changes or does not change due to its own laws (Tsofnas, 1995, p.8). Hence the theoretical position of the 'cold picture of the world' simplifies the problem not only of the nature knowledge, but also of the human knowledge. This position of cold picture was criticized by a famous physicist and philosopher W. Heisenberg (1987), who stressed that we should not discuss only the cold picture of the world, rather the attitude of the human spirit to nature and to itself is to be discussed. The idea of the independence of the object of knowledge from the subject of knowledge lost its heuristic meaning (Heisenberg, 1987, p.303). In our opinion, the 
spiritualization of the system of nature recognition should be sought on the lines of a 'warm picture of the world', which is based not on abstract rationalism, but on the principles of Christian and philosophical noology.

Human knowledge. Christian and philosophical noology cannot be limited to nature, but it also explores the problems of human knowledge. Undoubtedly, this human knowledge is the mix of number of sciences; however, we follow only outlined foundations, as human being and God are revealed, created and uncreated being in the noology.

There are several important characters of a human being, such as creative and intellectual abilities, spiritual orientation towards scientific, philosophical, religious and artistic abstraction, and the conscience of supernatural essence. It means that a human is rooted in terrestrial nature, cosmic nature, materialistic and energetic and informational elements of the Universe. A human is also rooted in supernatural and divine spheres. Therefore, it is the mosaic of two worlds natural and supernatural, or earthly and heavenly. At a certain stage of his development, a human realizes his own affiliation through the revelation of God. This dual human nature determines the dynamic tension that feeds the culture, including the ecological, and creates a variety of forms of social life of people. Therefore, it is important in the process of human knowledge to explore the main relationship between natural and supernatural conscience existing in the human and focusing on the spiritual and supernatural aspects of development, self-knowledge and opportunities leading to self-realization of a human. The knowledge of human must be appreciated in such a way that a spiritual motif is created for a human being, which may inspire him to a constant self-perfection. Consequently, directing to eternity, the kingdom of heaven, a human must give kindness, love and infinite space (Vasianovych and Onyshchenko, 2012, pp.5357).

In pursuit of Christian philosophical noology, human knowledge is closely connected with the knowledge of God. While connecting with God, all the noological abilities of man - imaginationintuition-mind, faith-conscience-will, love-joy-hope, and others - are involved. Through beliefs the person understands deeper and sees further deeply all the processes associated with the solution of environmental problems. Nevertheless, certain illusions may appear on the path of knowledge of God. Sensual illusion, intellectual illusion and moral-volitional illusion.

Sensual illusion. It is typical for those who believe that, for the knowledge of God, an inner sense is essential. This leads to the belief that God and spirituality become one of such pleasant sensations. Because our sensational and emotional states are unstable, changeable and modifiable with the changing moments of 'cooling', one sometimes loses desires to acquire knowledge of God and feels depressed when no positive feeling comes.

Intellectual illusion. This is the concept in which people try to know and love God through using mind. According to such people, the knowledge of God is primarily an intellectual matter. In this approach, God acts as a pure object of knowledge outlined by limited human abilities and schemes. Intellectual illusion is based on rational knowledge.

Moral-volitional illusion. Under this concept, in quest of the knowledge of God, a man absolves freedom and morality. Volitional human does not learn to thank God for the life he has been given by God along with the earthly gifts created by God. Certainly, a person believes in oneself more and considers himself or herself better than others. God, according to the logic of such a 
person, should be the one who rewards or punishes in line of strict criteria of human justice. Moreover, the moral and volitional illusion of knowledge of God has no concept of evil will, but absolutization of the will and freedom along with faith and conscience (Vasianovych and Onyshchenko, 2012, pp.59-60).

Conclusively, it is said that: 1) to know God we must be with pure heart, high intellect, strong will, and good thoughts; 2) ecological ethics will be able to influence the process of using nature effectively; and (3) humanization of the technosphere needs knowledge of nature, knowledge of human and knowledge of God interplay in close interconnection and interaction.

\section{Ecological Ethics and Problems of Humanization of the Technosphere}

Nevertheless, environmental ethics should not be reduced to ethical issues with partial inclusion of current ecological issues. Otherwise, it will treat ethics primarily as the anthropological, not as belonging to ecological science. The norms and rules of ecological ethics must intuitively intercept and synthesize the biological laws and social norms that have evolved during the history of mankind. Depending on the mode of production, culture and technology, certain historical periods were dominated by certain ethical principles or ethical and ecological imperatives that were changing constantly. It is no coincidence that environmental imperatives are followed clearly in different religions of the world.

One of the fundamental attributes of environmental ethics is the concept of "ecological consciousness", which in turn is interrelated with the notion of "moral consciousness". The structure of moral consciousness can be comprehended on the basis of the spiritual and mind's understanding of unity and interdependence of human consciousness. The human consciousness determines the process of formation of consciousness and promotes awareness of significant relationships that help guide the thinking of new forms and ideas in the spiritual and practical development of the world. Environmental consciousness begins to intensify environmental activities, thus showing the regulatory function of consciousness and thinking about practical activity (Arjjumend, 2017). That is why environmental consciousness is not only a reflection of activity concerning the protection of nature, but also a point of attitude towards it. Ecological consciousness and ecological thinking must assess adequately the environmental situation, the ability to correlate human actions with the actions of other beings. Scholars argue that the process of evolutionary (rectilinear) thinking is taking place actively in modern times; and it is leading to nonlinear thinking as described in the theory of synergetics (Vasianovych and Onyshchenko, 2012, pp.68-70). This direction is based on interdisciplinary research and studies inculcating the processes of self-organization and formation of new orderly structures belonging to physical, biological, social, informational and other sciences.

New methodological thinking is characterized by number of worldviews linking philosophical and noological features. Modern methodological consciousness tends to maximize the full constructivism of cognitive activity. Under the influence of mathematization and computerization, this tendency occupies both philosophical and pedagogical research, which are based on complex noological and synergetic ideas and principles.

Nonlinear processes are those that are studied in the theory of disasters and the theory of bifurcation. These processes consist of self-organization of unstable structures, self-generation of unbalanced systems, and spontaneous compaction of space and time. In turn, the outside world 
appears as a grandiose cooperation between autonomous universes interacting with one another: physical space, biospace, anthropospace and others. All this directly relates to environmental ethics, which is intended to study the conditions for the formation of love for nature. It is thus argued that ecological education is an important component of cultural and educational activities.

The result of the individual moral and ecological consciousness are the deep moral and spiritual beliefs that are realized in behavior and practical activity of a human being. Modern ecological thinking should cover all levels of social life - political, economic, cultural, etc. In particular, the ethical and ecological sciences are gaining growing attention in the technological process of human activity. Dehumanization of the modern technosphere is taking place in terms of global pollution of air and water bodies, alteration of landscapes, destruction of animal and plant worlds, destruction of soils, clogging of the near-space, depletion of ozone layer, etc. Such processes often occur as a result of violations by production technologies, human irresponsibility, and a lack of humanist culture (Arjjumend, 2017).

The dispiriting technosphere works according to the laws of a complex mechanism with ruthless coercion and terrible results. Technological mass culture has become a means of thoughtless entertainment, not spiritual enrichment and improvement of people. Animals, plants, ecosystems, biomes and mass of people are subject to the rhythms of the man-made process. Therefore, important for scientists is to clarify the essence of the technical universe, to identify the patterns and limits of technical activity, to establish the extent of the expansion of technology, to study the cultural, educational, ethical, environmental, spiritual and moral dimensions of the technosphere, and to take into account the humanistic aspects of technical development. According to scientists, "there is a need to bring ethicists, scientists and biodiversity managers together in a collaborative effort to study and inform methods of ethical analysis and problem solving in ecological research and biodiversity management" (Minteer and Collins, 2005). Finally, environmental ethics includes a system of environmental values and responsibilities of a person.

Depending on the relationship of a man with the world, the values are divided into material and spiritual values; depending the level of generality, it is divided into the concrete and the abstract values; and depending on the way of identification, it is bifurcated into the situational and stable values. A common classification of values divides the values depending on the criterion of membership: personal (individual), group (collective), social, national and universal values (Budnyk and Mazur, 2017).

\section{Spiritual and Moral Principles of Nature Management}

The devastating impact of the technosphere on the biosphere and people's lives becomes possible on the basis of radical transformations in technologies, materials, communications, and alike. In place of dangerous and inappropriate technologies, bionics technologies should be promoted. Summarizing the latest trends of nature management, one can focus on two global approaches: first, the informational and humanistic approach (Krysachenko, 1996, p.107); second, ecological and bionic approach.

Informational and humanistic use of nature. Changing the emphasis and priorities in relation to the world and man is manifested in primacy of universal values, the formation of a peculiar philosophy of the right to live with nature, the awareness of the need for a moral imperative as a regulator of the world (Krysachenko, 1996). So, ethical and ecological idea of using the nature is 
described and emphasized around the necessity of taking into account the organization and evolution of a being along with the harmonization of the relations between human and nature. Humanitarian and ethical priorities should keep civilization on the path to sustainable development by preventing ecological crises.

The ecological and bionic type of nature management proves the necessity of research and modeling of wildlife. Under this approach, particular attention is given to the problems of nature conservation, the development of technical civilization and culture, and the resolute limitation of technocracy. Therefore, today it is necessary to take into account the positive aspects of different approaches in the field of moral ecologization, knowledge of animate and inanimate nature, the development of ethical and ecological thinking in order to preserve a healthy environment, and the preservation of humanity on the planet Earth.

\section{Conclusion}

In modern rapidly changing world, it is very important to form a new methodological thinking in relation to the environment on the principles of environmental ethics. The ecological ethics has philosophical base with ecological consciousness, ecological thinking, environmental values, etc. In such a context, the strategy and approach of ecological activity of a human should promote the humanization of the technosphere. Society as a social component also plays an important role in the natural human environment and in the Human Ecology (Wyrostkiewicz, 2007). The environmental ethics disciplines a key role in accomplishing humanization of technosphere. Environmental ethics encompasses the development of ethical, moral, spiritual and aesthetic principles and norms that govern the relation of human with the nature. It is linked to noology which directs the human world's outlook on nature, human knowledge and the knowledge of God in order to preserve life on Earth. Summarizing the latest processes of modern management of nature, it is worthwhile to identify two global approaches - informational and humanistic, and eco-bionics. Suggested further areas of research include: the role and place of the newest pedagogical technologies in the education of spiritual and moral personality; raising the level of ecological literacy of citizens in the context of solving global environmental problems; functions of ecological culture in the spiritual life of society; technocracy as an anti-culture and a threat to human life; etc.

\section{Reference}

Amanuel, W., Yimer, F. and Karltun, E. (2018). Soil organic carbon variation in relation to land use changes: the case of Birr watershed, upper Blue Nile River Basin, Ethiopia. Journal of Ecology and Environment, 42:16. Doi: https://doi.org/10.1186/s41610-018-0076-1. Available online at: https://jecoenv.biomedcentral.com/articles/10.1186/s41610-018-0076-1

Arjjumend, H. (2017). Regulatory chill, corporate takeover and environmental governance. International Journal of Current Advanced Research, 6(12): 7923-7934. Doi:10.24327/ijcar.2017.7934.1254

Arjjumend, H., Shibata, S., Fakana, S.T. (2018). Ecosystem Services of in Nechisar National Park, Ethiopia: Identifying the Challenges and Conservation Measures. Journal of Global Resources, 4(02): 18-29.

Budnyk, O. and Mazur, P. (2017). The Hierarchy of Values Among Young People from Schools in the Mountainous Regions (Comparative study on the example of Poland and Ukraine). The New Educational Review, 47(1): 53-65. Doi: 10.15804/tner.2017.47.1.04. 
Danyliuk, L. (2018). The River Basin Principle of Water Resources Management in the Legislation of the European Union and Ukraine. Journal of Vasyl Stefanyk Precarpathian National University, 5(2): 99-106. Doi: 10.15330/jpnu.5.1.99-106.

Fromm, E. (1976). To Have or To Be? New York: Harper \& Row.

Heyzenberh, V. (1987). Steps beyond the horizon, translated, "Progress", Moscow (in Russian).

Jeong, Heon-Mo, Kim, Hae-Ran, Hong, Seungbum and You, Young-Han (2018). Effects of elevated $\mathrm{CO}_{2}$ concentration and increased temperature on leaf quality responses of rare and endangered plants. Journal of Ecology and Environment, 42:1. Doi: https://doi.org/10.1186/s41610-017-0061-0. Available online at: https://jecoenv.biomedcentral.com/articles/10.1186/s41610-017-0061-0

John, Paul II (1993). Church and social problems. Encyclical Letter "Centesimus annus", Lviv (in Ukrainian).

Körner, C. (2003). Alpine plant life: functional plant ecology of high mountain ecosystems (2nd ed.). Heidelberg: Springer Berlin.

Kostytskiy, V. (2018). Ensuring Ecological Safety or Ensuring a Favorable Environment: Theoretical and Legal Justification of the Function of a Modern Ecological State. Journal of Vasyl Stefanyk Precarpathian National University, 5(2):25-32. Doi: 10.15330/jpnu.5.1.25-32.

Krysachenko, V. S. (1996). Ecological culture, "Zapovit”, Kyiv (in Ukrainian).

Lyakhovych, D. (1995). Lectures on metaphysics, Lviv (in Ukrainian).

Minteer, B.A. and Collins, J.P. (2005). Ecological ethics: Building a new tool kit for ecologists and biodiversity managers. Conservation Biology, 19:1803-1812. Doi: https://doi.org/10.1111/j.1523-1739.2005.00281.x

Minteer, B.A. and Collins, J.P. (2008). From environmental to ecological ethics: toward a practical ethics for ecologists and conservationists. Science and Engineering Ethics, 14(4): 483-501. Doi: 10.1007/s11948-008-9087-0.

Planck, M. (1958). Physikalische Abhandlungen und Vorträge (Bd. 1-3). Braunschweig (in German).

Schweitzer, A. (1992). Reverence for Life [Ehrfurcht vor dem Leben]. Moscow: Progress Publishing House (in Russian).

Shynkaruk, V. (ed.) (1986). Philosophical Dictionary, Kyiv (in Ukrainian).

Tsofnas, A. (1995). Complementarity of the outlook and worldview, [in:] Philosophical and sociological thought, 1-2: 5-22 (in Ukrainian).

Vasianovych, H. and Onyshchenko, V. (2012). Noology of a Personality, Lviv (in Ukrainian).

Wyrostkiewicz, M. (2007). Human Ecology. Person and its environment from a moraltheological perspective. Lublin: KUL (in Polish). 